\title{
Assessment of Birth Preparedness and Complication Readiness among Pregnant Mothers Attending Ante Natal Care Service in Mizan-Tepi University Teaching Hospital, South West Ethiopia
}

\author{
Bayu Begashaw ${ }^{1^{*}}$, Yared Tesfaye ${ }^{1}$, Eminet Zelalem ${ }^{2}$, Ujulu Ubong ${ }^{3}$ and Abera Kumalo ${ }^{4}$ \\ ${ }^{1}$ Department of Public Health, MizanTepi University, MizanAman, Ethiopia \\ ${ }^{2}$ Mizan Health Center, Mizan Aman, Ethiopia \\ ${ }^{3}$ Gambella Regional Health Bureau, Gambela, Ethiopia \\ ${ }^{4}$ Department of Biomedical Sciences, MizanTepi University, Mizan Aman, Ethiopia
}

"Corresponding author: Bayu Begashaw, Department of Public Health, Mizan Tepi University, Mizan Aman, Ethiopia; Tel: +251924693611; E-mail: baybeg121@gmail.com

Received date: February 1, 2017; Accepted date: February 26, 2017; Published date: March 7, 2017

Copyright: ( $) 2017$ Begashaw B, et al. This is an open-access article distributed under the terms of the Creative Commons Attribution License, which permits unrestricted use, distribution, and reproduction in any medium, provided the original author and source are credited.

\begin{abstract}
Background: Every pregnancy is risk of having life-threatening obstetric complications. A birth preparedness package promotes active preparation and assists in decision-making for healthcare seeking in case of such complication. Although its importance is fact, it is low in Ethiopia.
\end{abstract}

Objective: To assess how pregnant women in Mizan Tepi University Teaching Hospital prepare for delivery and in the occurrence of complication practice and its associated factors, southwest Ethiopia.

Method: A facility based cross sectional study was conducted in antenatal clinic of Mizan Tepi University Teaching Hospital on a sample of 392 pregnant women in 2016. Data was collected using pre-tested structured questionnaire which was adapted from previous similar studies. Data was collected, checked and reviewed on daily basis by supervisors. The collected data were analyzed using SPSS version 21 software. Bivariate analyses was done to identify factors associated with birth preparedness and complication readiness and those found significant ( $p$-value $\leq 0.25$ ) were entered in the multivariate logistic regression analysis. The results were presented in frequency table, odds ratio and $95 \%$ confidence interval.

Results: Of the sample mothers, 392 making response rates of $98.7 \%$ were successfully interviewed. Among these, $51 \%$ of them were identified place for their recent birth whiles almost half of them $49 \%$ were not identified place for their recent birth. Majority of women $77.6 \%$ were heard about birth preparedness and complication Readiness. High proportions were got information from health professionals $75.8 \%$. Among the factors considered for birth preparedness and Complication Readiness were lower monthly income, maternal and husband education, maternal occupation showed statistically significant association.

Conclusion: The magnitude of birth preparedness and complication readiness was moderate in the study area. Preparedness in health system, ensuring competence, and motivations of workers are needed for promoting BPCR among the study population.

Keywords: Antenatal care; Birth preparedness; Complication readiness; Knowledge

\section{Background}

Birth preparedness and complication ( $\mathrm{BP} / \mathrm{CR})$ readiness is the course of action of planning for normal birth and anticipating the action needed in the case of emergency [1-3]. It is also an approach to promote utilization of skilled maternal and neonatal care timely, based on the assumption that preparing for child birth and being ready for complications reduces delay in obtaining this care [4-7].

Birth-preparedness and complication-readiness is a comprehensive package aimed at promoting timely access to skilled maternal and neonatal services. The birth preparedness package promotes active preparation and decision-making for delivery by pregnant women and their families. This emerged from the fact that a pregnant woman faces risk of sudden and unpredictable life threatening complications that could end in death or injury to herself or to her infant $[3,7-10]$. This is because complications such as hemorrhage are unpredictable and highly fatal if timely treatment is not obtained. The package of BPCR is a very important strategy in developing countries, where obstetric services are poor. There is also enough evidences from Nepal, Burkina Faso and India that promoting BPCR improves preventive behaviours, improves knowledge of mothers about danger-signs, and leads to improvement in care-seeking during obstetric emergency therefore reducing disability and death associated with child birth [11-13].

Unfortunately the utilization of skilled birth attendant is low even in settings where services are accessible. For past times maternal deaths are thought to occur due to three delays: delay in deciding to seek appropriate care; delay in reaching an appropriate health facility; and 
delay in receiving adequate emergency care once at a facility. In many societies in the world, cultural beliefs and lack of awareness inhibit preparation in advance for delivery of the expected baby. Since no action is taken prior to the delivery, the family tries to act only when labour begins [12-15]. The majority of pregnant women and their families do not know how to recognize the danger signs of complications. When complications occur, the unprepared family will waste a great deal of time in recognizing the problem, getting organized, getting money, finding transport and reaching the appropriate referral facility $[4,5,12,13]$. In Ethiopia; only $42 \%$ of pregnancies are unintended and more than half a million pregnancies are ended, More than 25,000 women died due to pregnancy and childbirth complications each year nationally and of the total (553) maternal deaths in the facilities, $74 \%$ are caused by direct while $26 \%$ are caused by indirect obstetric complication [16-18].

Despite the birth preparedness and complication readiness strategy was aimed to improve awareness of women about danger signs of pregnancy related complication and further importance of maternal and neonatal health services, limited information is documented about the practice of birth preparedness and complication readiness among recently delivered mother and associated factors in south west Ethiopia particularly in the study area. Therefore, this study aims to assess practice of birth preparedness and complication readiness among ANC attendant pregnant women in Mizan-Tepi University teaching hospital, southwest Ethiopia.

\section{Methods and Material}

\section{Study area and period}

The study was conducted in Mizan-Tepi University Teaching Hospital located in Bench Maji zone, south west Ethiopia from March 25 to April 25, 2016. Bench-Maji Zone with capital of Mizan-Aman town, Aman sub town kebele 02 and landed on $97,560 \mathrm{~m}^{2}$. It is serving about two million people who live in Bench-Maji, Sheka, Kaffa zones and fourdistricts of Gambela region that demarked the Zone.

The Hospital provides emergency and regular OPD service, Inpatient treatment and care, minor and major surgery, $\mathrm{MCH}$, gynecology and obstetrics, laboratory, radiology, pharmacy, psychiatry, ophthalmic, VCT and ART services. On the other hand the hospital is serving as a teaching hospital by cooperating with Jimma University Specialized and Teaching Hospital and Mizan-Aman Health Science College.

\section{Study design}

The facility based descriptive cross-sectional was used.

\section{Source of population}

ANC service attendant pregnant women in Mizan-Tepi University Teaching Hospital were the source population.

\section{Study population}

The study population was pregnant mothers who were ANC attendants during study period that means in actual study were the study population.

\section{Eligibility criteria}

Inclusion criteria: Pregnant women on visits of ANC who were willing to be included during interview.

Exclusion criteria: Mothers who were seriously ill or unable to communicate were excluded.

\section{Sample Size Determination}

The sample size is calculated using a formula for estimation of single population proportion 389 women were taken as sample based on $95 \%$ Confidence interval and 5\% margin of error, $16 \%$ proportion of birth preparedness and complication readiness among women in Jimma Zone 23.3\% [16].

By adding 5\% non-response rate, which is 19 and the final Sample size was 397.

\section{Sampling procedure/Technique}

A systematic random sampling technique was employed to select the study subjects. The sample size was proportionally allocated to the selected health facilities using the two months average client flow. The sampling interval was calculated to be $(K=n / N)$.

\section{Data collection instrument and method}

The data collection tool was adapted from JHPIEGO: Maternal and Neonatal Health on monitoring birth preparedness and complication readiness. The adapted questionnaire was modified and contextualized to fit the local situation and the research objective. The questionnaire was prepared first in English, translated into Amharic, and then back into English by fluent speakers of both languages to check its consistency. Data on socio-demographic factors, obstetric factors, and knowledge and practice regarding birth preparedness and complication readiness were collected using a pre-tested and structured questionnaire. Data were collected through face-to-face interviews after training both data collectors and supervisors. The pretesting was conducted in $5 \%$ of the sample size of pregnant mother in Mizan Health Center. After review of the instruments all suggested revisions were made before being administered in the actual study.

Two data collectors and one supervisor were recruited to participate in the study. The selection criteria for data collectors were those individual who had Diploma in nursing. The supervisors have Bachelor degree in public health or nursing and have previous experiences.

\section{Data quality assurance}

Training was given for data collectors for three days to ensure the completeness and consistency of information during data collection. The questionnaire was pre-tested before data collection. The investigators and supervisors was checked before receiving the filled questionnaire from each data collector and there was meeting at the end of data collecting time to discuss for improvement.

\section{Data processing and analysis}

On each days of data collection, all data collectors checked the data for its completeness and missing information at each point. The collected data was reviewed, coded, entered and analyzed using SPSS software version 16 . And the analyzed data was presented by frequency and percentage and by tables. 
Citation: Begashaw B, Tesfaye Y, Zelalem E, Ubong U, Kumalo A (2017) Assessment of Birth Preparedness and Complication Readiness among Pregnant Mothers Attending Ante Natal Care Service in Mizan-Tepi University Teaching Hospital, South West Ethiopia. Clinics Mother Child Health 14: 257. doi:10.4172/2090-7214.1000257

Page 3 of 7

\begin{tabular}{|c|c|c|c|}
\hline Back ground variables & Categories & Frequency & Percent \\
\hline \multirow[t]{5}{*}{ Age of the mother } & $15-19$ & 44 & 11.2 \\
\hline & $20-29$ & 272 & 69.4 \\
\hline & $30-39$ & 66 & 16.8 \\
\hline & $\geq 40$ & 10 & 2.6 \\
\hline & Total & 392 & 100 \\
\hline \multirow[t]{5}{*}{ Marital status } & Single & 6 & 1.5 \\
\hline & Married & 376 & 96 \\
\hline & Divorced & 2 & 0.5 \\
\hline & Widowed & 8 & 2 \\
\hline & Total & 392 & 100 \\
\hline \multirow[t]{6}{*}{ Women's educational status } & $\begin{array}{l}\text { Unable to read and } \\
\text { write }\end{array}$ & 144 & 36.7 \\
\hline & Able to read and write & 162 & 41.3 \\
\hline & Primary education & 28 & 7.7 \\
\hline & Secondary education & 30 & 7.1 \\
\hline & Tertiary education & 28 & 7.1 \\
\hline & Total & 392 & 100 \\
\hline \multirow[t]{5}{*}{ Religion } & Orthodox & 134 & 34.2 \\
\hline & Protestant & 202 & 51.5 \\
\hline & Muslim & 54 & 13.8 \\
\hline & Other & 2 & 0.5 \\
\hline & Total & 392 & 100 \\
\hline \multirow[t]{6}{*}{ Ethnicity } & Bench & 192 & 49 \\
\hline & Kaffa & 69 & 17.6 \\
\hline & Amhara & 69 & 17.6 \\
\hline & Oromo & 42 & 10.7 \\
\hline & Others & 20 & 5.1 \\
\hline & Total & 392 & 100 \\
\hline \multirow[t]{3}{*}{ Family size } & $<$ four & 238 & 60.7 \\
\hline & $\geq$ four & 154 & 39.3 \\
\hline & Total & 392 & 100 \\
\hline \multirow[t]{6}{*}{ Mothers occupation } & Private worker & 86 & 21.9 \\
\hline & Government worker & 50 & 12.8 \\
\hline & House wife & 184 & 46.9 \\
\hline & farmers & 60 & 15.3 \\
\hline & Others & 12 & 3.1 \\
\hline & Total & 392 & 100 \\
\hline
\end{tabular}

\begin{tabular}{|l|l|l|l|}
\hline \multirow{4}{*}{ Mothers income } & $<200$ & 200 & 51 \\
\cline { 2 - 4 } & $200-500$ & 111 & 28.3 \\
\cline { 2 - 4 } & $500-1000$ & 29 & 7.4 \\
\cline { 2 - 4 } & $>1000$ & 52 & 13.3 \\
\cline { 2 - 4 } & Total & 392 & 100 \\
\hline \multirow{3}{*}{ Number of children } & $\leq 3$ children & 56 & 14.3 \\
\cline { 2 - 4 } & $>3$ children & 336 & 85.7 \\
\cline { 2 - 4 } & Total & 392 & 100 \\
\hline
\end{tabular}

Table 1: Socio-demographic characteristics of respondents in In Mizan-Tepi University Teaching Hospital, South West Ethiopia, 2016.

\begin{tabular}{|c|c|c|c|}
\hline Back ground variables & Categories & Frequency & Percent \\
\hline \multirow[t]{3}{*}{ Identified place for your recent birth } & No & 192 & 49 \\
\hline & Yes & 200 & 51 \\
\hline & Total & 392 & 100 \\
\hline \multirow[t]{3}{*}{ Identified skilled birth attendant } & No & 109 & 27.8 \\
\hline & Yes & 283 & 72.2 \\
\hline & Total & 392 & 100 \\
\hline \multirow[t]{3}{*}{ Saved money } & No & 288 & 73.5 \\
\hline & Yes & 104 & 26.5 \\
\hline & Total & 392 & 100 \\
\hline \multirow{3}{*}{$\begin{array}{l}\text { Identified means of transport to } \\
\text { place of delivery }\end{array}$} & No & 151 & 38.5 \\
\hline & Yes & 241 & 61.5 \\
\hline & Total & 392 & 100 \\
\hline \multirow[t]{3}{*}{ Identified blood donor } & No & 331 & 84.4 \\
\hline & Yes & 61 & 15.6 \\
\hline & Total & 392 & 100 \\
\hline
\end{tabular}

Table 2: Birth Preparedness and Complication Readiness components in among pregnant mothers in Mizan-Tepi University Teaching Hospital, South West Ethiopia, 2016.

\section{Ethical Consideration}

Approval was obtained from the Mizan-Tepi university department Of Public Health. Permission letters was obtained from Mizan-Tepi University. Informed oral consent was obtained from the participant after a comprehensive explanation of the purpose and procedure.

\section{Results}

\section{Socio-demographic characteristics of respondents}

A total of 392 study subjects were participated in the study making response rates of $98.7 \%$. The majority of women age fall in $20-29$ years age group $272(69.4 \%)$. Among the total respondents almost all, 376 
Citation: Begashaw B, Tesfaye Y, Zelalem E, Ubong U, Kumalo A (2017) Assessment of Birth Preparedness and Complication Readiness among Pregnant Mothers Attending Ante Natal Care Service in Mizan-Tepi University Teaching Hospital, South West Ethiopia. Clinics Mother Child Health 14: 257. doi:10.4172/2090-7214.1000257

Page 4 of 7

(96\%) were married while the rest $4 \%$ were single, divorced and divorced. Most of the respondents, 202 (51.5\%) were protestants by Orthodox religion 134 (34.2\%). Regarding educational background, majority of women were able to read (had no formal education) followed by unable to read in their educational status were162 (41.3\%) and $144(36.7 \%)$ respectively. Concerning ethnicity majority were Bench 192 (49\%), Kaffa and Amhara comprises equal proportion with $162(17.6 \%)$ followed by Oromo 42 (10.7\%) (Table 1).

\begin{tabular}{|c|c|c|c|}
\hline Variables & Categories & Frequency & Percent \\
\hline \multirow[t]{3}{*}{ Heard about BP/CR } & No & 88 & 22.4 \\
\hline & Yes & 304 & 77.6 \\
\hline & Total & 392 & 100 \\
\hline \multirow[t]{5}{*}{ Source of information to know about BP/CR } & Your mother & 14 & 3.6 \\
\hline & Married media & 30 & 7.7 \\
\hline & Health professionals & 297 & 75.8 \\
\hline & Your friends & 51 & 13 \\
\hline & Total & 392 & 100 \\
\hline \multirow[t]{3}{*}{ Any previous serious health problems related to the pregnancy? } & No & 364 & 92.9 \\
\hline & Yes & 28 & 7.1 \\
\hline & Total & 392 & 100 \\
\hline \multirow[t]{4}{*}{ What problems did you experienced? } & Vaginal bleeding & 24 & 6.1 \\
\hline & Swollen hands/face & 2 & 0.5 \\
\hline & Blurred vision & 2 & 0.5 \\
\hline & Total & 28 & 7.1 \\
\hline \multirow[t]{4}{*}{ Danger signs those endanger the life of a pregnant woman? } & Vaginal bleeding & 277 & 70.7 \\
\hline & Swollen hands/face & 61 & 15.6 \\
\hline & Blurred vision & 54 & 13.8 \\
\hline & Total & 392 & 100 \\
\hline \multirow{5}{*}{$\begin{array}{l}\text { Danger signs during labor and childbirth that can endanger the life } \\
\text { of a pregnant woman? }\end{array}$} & Severe vaginal bleeding & 208 & 53.1 \\
\hline & Prolonged labor (>12huors) & 102 & 26 \\
\hline & Convulsion & 40 & 10.2 \\
\hline & Retained placenta & 42 & 10.7 \\
\hline & Total & 392 & 100 \\
\hline \multirow{4}{*}{$\begin{array}{l}\text { Danger signs during the first } 2 \text { days after birth that could endanger } \\
\text { the life of the woman? }\end{array}$} & Severe vaginal bleeding & 233 & 59.4 \\
\hline & Foul-smelling vaginal discharge & 108 & 27.6 \\
\hline & High fever & 51 & 13 \\
\hline & Total & 392 & 100 \\
\hline \multirow{4}{*}{$\begin{array}{l}\text { Danger signs the first } 7 \text { days after birth that could endanger the } \\
\text { life of a newborn baby? }\end{array}$} & Difficult or fast breathing & 61 & 15.6 \\
\hline & Yellow skin/eye color (jaundice) & 16 & 4.1 \\
\hline & Poor sucking or feeding & 219 & 55.9 \\
\hline & $\begin{array}{l}\text { Plus, bleeding, or discharge from around the umbilical } \\
\text { cord }\end{array}$ & 16 & 4.1 \\
\hline
\end{tabular}


Citation: Begashaw B, Tesfaye Y, Zelalem E, Ubong U, Kumalo A (2017) Assessment of Birth Preparedness and Complication Readiness among Pregnant Mothers Attending Ante Natal Care Service in Mizan-Tepi University Teaching Hospital, South West Ethiopia. Clinics Mother Child Health 14: 257. doi:10.4172/2090-7214.1000257

Page 5 of 7

\begin{tabular}{|c|c|c|c|}
\hline & Baby very small & 50 & 12.8 \\
\hline & Convulsions/spasms/rigidity & 2 & 0.5 \\
\hline & Lethargy/unconsciousness & 28 & 7.1 \\
\hline & Total & 392 & 100 \\
\hline \multirow{4}{*}{$\begin{array}{l}\text { What are the basic care that can be provided to a newborn baby } \\
\text { immediately after birth? }\end{array}$} & Exclusive breastfeeding & 296 & 75.5 \\
\hline & Dry and wrap eye & 32 & 8.2 \\
\hline & Cord care & 64 & 16.3 \\
\hline & Total & 392 & 100 \\
\hline
\end{tabular}

Table 3: Maternal Knowledge on key danger sign of pregnancy, labour and post partum in Mizan-Tepi University Teaching Hospital, South West Ethiopia, 2016.

\section{Birth preparedness and complication readiness components in among pregnant mothers}

Among the total study participants, 200 (51\%) of them were identified place for their recent birth while almost half of them 192 (49\%) were not identified place for their recent birth. Majority of respondents $283(72.2 \%)$ identified skilled birth attendant while only 109 (27.8\%) of them were not identified skilled birth attendant for their birth. The least number of respondents were saved money and identified blood donors for their birth with having 104 (26.5\%) and 61 (15.6\%) respectively.

In general 161 (41.1\%) of mothers have practice of BPCR (Table 2).

\section{Maternal knowledge on key danger sign of pregnancy, labour and post partum}

Majority of women 304 (77.6\%) were heard about Preparedness and Complication Readiness. High proportions were got information from health professionals 297 (75.8\%). Few mothers were encountered serious health problem in their recent previous pregnancy about 28 (7\%). among the problems hemorrhage comprises 24 (85.7\%) (Table 3).

\section{Maternal birth preparedness and complication readiness and associated factors}

Maternal birth preparedness and complication readiness was associated with their monthly income, education, still birth and saving money were variables independently affecting $\mathrm{BP} / \mathrm{CR}$ while other variables were controlled for possible confounding variables.

Those mothers who have monthly income 500-1000 Ethiopian birr per month were five times more likely prepared for birth and ready for complication than bellow 200 birr per month with $\mathrm{AOR}=4.8$, at $95 \%$ CI $(2.1,11.4)$ with $\mathrm{p}$ value $<0.05$. Other income categories were also more likely prepared for birth and ready for complication.

Other variable is maternal education in which mothers who were able to read and write were two times more likely prepared for birth and ready for complication than unable to read and write with $\mathrm{AOR}=1.9$, at $95 \% \mathrm{CI}(1.1 .3 .4)$ with $\mathrm{p}$ value $<0.05$. Also saving money is associated with Maternal birth preparedness and complication readiness by which mothers who saved money were less likely better than their counter parts with $\mathrm{AOR}=0.35$, at $95 \% \mathrm{CI}(0.2,0.56)$ with $\mathrm{p}$ value $<0.01$. Mothers whom had no still birth were less likely better than their counter parts with $\mathrm{AOR}=0.4$, at $95 \%$ CI $(0.12,0.91)$ with $\mathrm{p}$ value $<0.01$ (Table 4 ).

\section{Discussion}

This study was conducted to assess prevalence of birth preparedness and complication readiness its associated factors among mothers in south western Ethiopia.

The finding of this study revealed the prevalence of birth preparedness and complication readiness was $41.1 \%$. It implies for the need of both community and facility-level interventions to improve maternal survival and the importance of quality ANC interventions to increase BPCR practice in the setup. This finding is higher than the study conducted in Ghana, Nepal, Bale robe Ethiopia and India [1], Adigrat 22\% [19] and Robe Oromiaregion 16.5\% [15]. This difference may be due to MDGs implementation and difference in the study setting.

Maternal education has significant effect on BPCR. This result is in line with the studies conducted in other parts of Ghana, Eretria, Robe, Nigeria $[12,15,20,21]$. This might be due to the fact that knowledge and awareness towards maternal and child health will be increased as the education level increases.

In the current study both mother and husband occupation were not significant factors of BP CR. This is inconsistent with studies done in Uganda and Nigeria [22]. The difference could be impact of the government's free provision of ambulance service, medical supply and other services for maternal and child health during birth.

In this study pregnant women who had no history of still birth were negatively determined BPCR practice. This might be due to those pregnant women could predict serious complications from their previous experiences as similar study done in Ethiopia [18].

In this study those pregnant women who have saved money were less likely to be prepared for birth and its complication than those who didn't save money. This finding is not in line with the previous studies done in Tanzania, Uganda and Dire Dawa city in Ethiopia $[15,13,20,23-26]$. This might indicate that delivery charge free service for maternal and child care are being valuable and societies are utilizing well. 
Citation: Begashaw B, Tesfaye Y, Zelalem E, Ubong U, Kumalo A (2017) Assessment of Birth Preparedness and Complication Readiness among Pregnant Mothers Attending Ante Natal Care Service in Mizan-Tepi University Teaching Hospital, South West Ethiopia. Clinics Mother Child Health 14: 257. doi:10.4172/2090-7214.1000257

Page 6 of 7

In our findings health information and education has no effect on $\mathrm{BP}$ and CR. This is not similar with others studies [27-30]. This may implies that most of our study area mothers come from pastoral and semi pastoral rural areas.

\begin{tabular}{|c|c|c|c|c|}
\hline \multirow[b]{2}{*}{ Variables } & \multicolumn{4}{|c|}{ Practice of BP/CR } \\
\hline & Yes & No & COR $(95 \%$ C.I) & AOR (95\% C.I) \\
\hline \multicolumn{5}{|c|}{ Women's educational status } \\
\hline Unable to read and write & 94 & 50 & 1 & \\
\hline Able to read and write & 20 & 10 & $3.4(1.923,5.958)^{*}$ & $1.9(1.1 .3 .4)^{*}$ \\
\hline Primary education & 24 & 4 & $3.1(1.049,9.71)^{\star}$ & $1.5(0.6,4.5)$ \\
\hline Secondary education & 140 & 22 & $1.064(0.462,2.447)$ & $2.1(0.7,5.9)$ \\
\hline Tertiary education & 26 & 2 & $6.9(1.576,30.333)$ & $3(0.9,10)$ \\
\hline \multicolumn{5}{|l|}{ Husband education } \\
\hline Unable to read and write & 12 & 35 & 1 & 1 \\
\hline Able to read and write & 24 & 44 & $1.4(0.76,2.5)$ & $0.4(0.43,1.6)$ \\
\hline Primary education & 63 & 84 & $0.6(0.28,1.4)$ & $0.4(0.17,1.1)$ \\
\hline Secondary education & 46 & 60 & $1.4(0.75,2.6)$ & $0.6(0.25,1.2)$ \\
\hline Tertiary education & 16 & 8 & $3.6(1.4,9.8)^{*}$ & $0.8(0.25,3.1)$ \\
\hline \multicolumn{5}{|l|}{ Mothers income } \\
\hline$<200$ & 140 & 60 & 1 & \\
\hline $200-500$ & 21 & 8 & $2.5(1.383,4.683)^{*}$ & $3.6(2.1,6.2)^{\star}$ \\
\hline $500-1000$ & 95 & 16 & $1.1(0.472,2.682)$ & $4.8(2.1,11.4)^{\star}$ \\
\hline$\geq 1000$ & 48 & 4 & $5.1(1.775,14.902)^{*}$ & $3.6(1.4,8.9)^{*}$ \\
\hline \multicolumn{5}{|l|}{ Still birth } \\
\hline Yes & 18 & 10 & 1 & 1 \\
\hline No & 143 & $\begin{array}{l}22 \\
1\end{array}$ & $0.36(0.16,0.8)^{*}$ & $0.4(0.12,0.91)^{*}$ \\
\hline \multicolumn{5}{|l|}{ Saved money } \\
\hline Yes & 61 & 43 & $0.4(0.24,0.6)^{* *}$ & $0.35(0.2,0.56)^{* *}$ \\
\hline No & 100 & $\begin{array}{l}18 \\
8\end{array}$ & 1 & \\
\hline
\end{tabular}

Table 4: Association of socio-demographic characteristics and practice maternal birth preparedness and complication readiness among ANC attendants in MTUTH south West Ethiopia, 2016.

\section{Conclusion}

Our study showed that below half of pregnant women were well prepared for delivery and obstetric complication, but majority of pregnant women planned to deliver at home. Beyond this little proportion of pregnant women identified blood donor and transportation.

Our study showed maternal education, monthly income, history of past obstetric complications and saving money were factors affect
BPCR independently. This is similar with study done in Malawi [31]. For this reason health Information and Education should be provided for every mothers of reproductive age regardless of an educational status and monthly income on birth preparedness and complication readiness early. The government officials, executives, stakeholders and partners that are working in areas of maternal health should develop scientific approaches to advance birth preparedness at individual, household and community level.

\section{Competing Interests}

We declare that we have no competing interests exist.

\section{Acknowledgments}

We would like to thank Mizan Tepi University, College of Public Health and Medical Sciences for continuous support in under taking this research as well as to all mothers, data collectors and everybody under study.

\section{References}

1. Mekuaninte AG, Worku A, Tesfaye DJ (2016) Assessment of Magnitude and Factors Associated with Birth Preparedness and Complication Readiness Among Pregnant Women Attending Antenatal Clinic of Adama Town Health Facilities, Central Ethiopia. Euro J Prev Med 4: 32-38.

2. JHPIEGO (2004) Monitoring birth preparedness and complication readiness tools and indicators for maternal and newborn health.

3. Sumankuuro J (2016) Factors influencing knowledge and practice of birth preparedness and complication readiness in sub-saharan Africa? A narrative review of cross-sectional studies. Int J Com Med Publ Health 3: 3297-3307.

4. Goodburn E, Campbell O (2001) Reducing maternal mortality in the developing world: sector-wide approaches may be the key. BMJ 322: 917-920.

5. Central Statistical Agency (2014) Ethiopia Mini Demographic and Health Survey 2014, Addis Ababa, Ethiopia.

6. Iliyasu Z (2010) Birth Preparedness, Complication Readiness and Fathers' Participation in Maternity Care in a Northern Nigerian Community. Afri J Reprod Heal Mar. 14: 21-32.

7. Nandan D (2008) A study for assessing birth preparedness and complication readiness intervention in Rewa District of Madhya Pradesh.

8. Agbodohu DA (2013) Birth preparedness and complication readiness among expectant mothers at the ridge regional hospital, Accra.

9. Program NH (2001) Birth Preparedness and Complication Readiness? A Matrix of Shared Responsibilities. Matern Neonat Heal Prog 410: 1-7.

10. Soubeiga D, Gauvin L, Hatem MA, Johri M (2014) Birth Preparedness and Complication Readiness (BPCR) interventions to reduce maternal and neonatal mortality in developing countries: systematic review and meta-analysis. BMC Pregnancy Childbirth 14: 129.

11. Dhakal P and Shrestha M (2016) Knowledge on birth preparedness and complication readiness in Eastern Region of Nepal. Int J Nurs Mid 8: 75-80.

12. Affipunguh PK and Laar AS (2016) Assessment of knowledge and practice towards birth preparedness and complication readiness among women in Northern Ghana? A cross-sectional study. Int J Scien Rep 2: 121-129.

13. Idowu A, Deji SA, Aremu OA, Bojuwoye OM, Ofakunrin AD (2015) Birth Preparedness and Complication Readiness among Women Attending Antenatal Clinics in Ogbomoso, South West, Nigeria. Int J MCH AIDS 4: 47-56.

14. IMPAC (2006) Birth and emergency preparedness in antenatal care. 1-6. 